\title{
0 impacto das políticas públicas no desenvolvimento de arranjos produtivos locais: 0 caso do APL de ovinocaprinocultura em Quixadá, Ceará*
}

\author{
Janayna Arruda Barroso** \\ Alexandre Araújo Cavalcante Soares***
}

Sumário: 1. Introdução; 2. APLs como estratégia para o desenvolvimento local; 3. Políticas públicas para o desenvolvimento dos APLs; 4. Metodologia da pesquisa; 5. Contexto da pesquisa: o ambiente institucional Quixadá; 6 . Análise dos resultados; 7. Considerações finais.

Summary: 1 . Introduction; 2. LPAs as a strategy for local development; 3. Public policies for the development of LPAs; 4. Research methodology; 5. Research background: the Quixadá institutional environment; 6. Results analysis; 7. Final remarks.

Palavras-chave: políticas públicas; arranjos produtivos locais; desenvolvimento local.

KEY WORDs: public policies; local productive arrangements; local development.

Este artigo enfoca o papel das políticas públicas para o desenvolvimento de arranjos produtivos locais (APLs) na região Nordeste. Uma das formas de o governo alavancar os APLs é com a criação de políticas que apoiem o desenvolvimento dessas aglomerações de empresas. No Brasil, tais políticas de incentivo aos APLs têm se tornado consistentes e já se pode visualizar os resultados satisfatórios de sua implementação. Por meio de um estudo de caso, este artigo analisa o exemplo de um conjunto de políticas implementadas em um APL de ovinocaprinocultura na região Nordeste. A seguinte questão norteou o estudo: qual o impacto das políticas públicas implementadas no APL selecionado, em termos de desenvolvimento local e melhoria nas con-

\footnotetext{
* Artigo recebido em ago. e aceito em out. 2009.

** Mestre em administração pela Universidade de Fortaleza (Unifor) e professora da Faculdade Paraíso do Ceará (FAP). Endereço: Rua São Francisco, 1077 — São Miguel — CEP 63010-210, Juazeiro do Norte, CE, Brasil. E-mail: janaynaarruda@ymail.com.

**** Mestre em administração pela Universidade Estadual do Ceará (Uece) e professor da Universidade Federal do Ceará (UFC) — Campus Cariri. Endereço: Rua São Francisco, 1077 — São Miguel — CEP 63010-210, Juazeiro do Norte, CE, Brasil. E-mail: aacsoares@hotmail.com.
} 
dições de vida dos sujeitos? Adotou-se uma abordagem qualitativa, sendo levantadas evidências a partir de análise documental e entrevistas a 13 atores sociais locais. Constatou-se que as políticas públicas implementadas no APL de ovinocaprinocultura localizado no sertão de Quixadá, Ceará, tiveram um significativo impacto para os criadores da região, que têm experimentado melhoria nos processos de manejo do rebanho, ensejando melhor produção, o que representa ganho significativo para os participantes do APL.

The impact of public policies in the development of local production arrangements: the case of the LPA for sheep and goat raising in Quixadá, Ceará, Brazil

This article focuses on the public policies in the development of local productive arrangements (LPAs) (in Portuguese, APLs) in the Brazilian Northeast. One of the ways the government uses to leverage the LPAs is by creating policies that support the development of such agglomerations of firms. In Brazil, these LPA stimulus policies have been consistent and their satisfactory results can be noticed. This paper presents a case study of a set of policies implemented in an APL for goat and sheep raising in Quixadá, CE, in the Brazilian Northeast. The following question oriented the study: What is the impact of the public policies implemented in the chosen LPA, in terms of local development and improvement of the subjects lives? The study adopted a qualitative approach, and the data was obtained through the analysis of documents and through interviews with 13 local social actors. It revealed that such policies had a significant impact on the farmers, improving their cattle management processes, as well as their production, resulting in significant gains for the APL's participants.

\section{Introdução}

O Nordeste é uma das regiões que historicamente mais apresentam bolsões de pobreza, o que se contrapõe a sua riqueza cultural e natural. A criação da Agência de Desenvolvimento do Nordeste (Adene) tem evidenciado a tentativa do governo de minimizar os problemas econômicos e sociais da região. Esse quadro chama a atenção para as estratégias que vêm sendo utilizadas para apoiar o sistema de produção das pequenas e médias empresas (PMEs) e para o desenvolvimento das comunidades locais, já que o sistema local de PMEs pode contribuir positivamente para o desenvolvimento econômico de um país ou de uma região (Naretto, Botelho e Mendonça, 2004). Segundo Cassiolato e Lastres (2003), entre as transformações ocorridas nos últimos tempos, destaca-se o interesse sobre qual o papel que as PMEs podem ter na reestruturação produtiva, assim como no desenvolvimento de regiões e países.

O Brasil apresenta significativas concentrações espaciais de PMEs, formando os chamados APLs, tanto em regiões mais industrializadas quanto em 
regiões menos desenvolvidas, em setores tradicionais e em setores de alta tecnologia. "Os arranjos produtivos locais são concentrações regionais/locais de firmas que possuem elos (vertical/horizontal/multilateral) e que desenvolvem atividades coordenadas com algum fim em comum" (Câmara et al., 2005:1). De acordo com Cassiolato e Lastres (2003:3), "os APLs são aglomerações territoriais de agentes econômicos, políticos e sociais que apresentam vínculos". Assim, o APL é caracterizado pela existência da aglomeração de significativo número de empresas que atuam em torno de uma atividade produtiva principal.

O governo brasileiro tem despertado para a grande problemática do desemprego e para o crescente número de habitantes nas metrópoles. Como alternativa, tem percebido que os APLs podem ser uma estratégia para valorização do local, empregando pessoas da comunidade, evitando assim o êxodo para as metrópoles. Uma das formas de o governo alavancar os APLs é a criação de políticas que apoiem e ajudem no desenvolvimento dessas aglomerações de empresas. Essas políticas de incentivos aos APLs no país têm se tornado consistentes, já sendo possível visualizar resultados satisfatórios.

O Nordeste é uma região que tem grande aptidão para a pecuária, havendo uma relação histórica com a pecuária bovina de corte, que já exerceu importante papel na economia nordestina. Ultimamente, há um destaque no semiárido para pecuária bovina leiteira, mas que atualmente está enfrentando grandes problemas de competitividade, especialmente no segmento de pequenos produtores. Nesse contexto, a ovinocaprinocultura tem se tornado um negócio bastante promissor, em decorrência dos seguintes fatores: adaptação às condições locais, crescimento do mercado, oportunidade para todas as categorias de produtores e interesse do poder local pela atividade, com pretensão de inserção competitiva, direcionada para a visão sistêmica de cadeia produtiva.

Este trabalho busca analisar o impacto de políticas de desenvolvimento e fortalecimento de APLs, ilustrando a eficácia dessa política, através de um estudo de caso de sucesso em um APL de ovinocaprinocultura, na região Nordeste do Brasil. A seguinte questão norteou este estudo: qual o impacto das políticas públicas implementadas no APL selecionado no estado do Ceará? No que se refere à metodologia, esta pesquisa é de natureza qualitativa, utilizando-se do estudo de caso, onde serão analisadas e descritas a política e as ações que estão sendo implementadas no município de Quixadá, Ceará, que apoiam o APL de ovinocaprinocultura.

Nas duas próximas seções são apresentados uma discussão sobre a relação entre APLs, o desenvolvimento local e as políticas públicas de desenvolvimento de APLs. Nas demais seções são apresentados o percurso metodológico, os resultados do trabalho empírico e, por fim, as considerações finais. 


\section{APLs como estratégia para o desenvolvimento local}

Economias de aglomeração e inovação têm sido consideradas forças importantes que conduzem a competitividade crescente e a melhoria das condições de vida para pessoas que vivem em tais regiões (Piore e Sabel, 1984; Pyke, Becattini e Sengenberger, 1990; Storper, 1997). A importância dos estudos em aglomerações do tipo APLs vem crescendo pela relevância que essa estratégia vem ocupando para o desenvolvimento de localidades e regiões. Esse tipo de aglomeração de empresas tem resultado no aumento da renda e nível de emprego, nas exportações e importações, assim como na difusão de conhecimentos regionais para a inserção da comunidade local no âmbito social. De acordo com Crocco e outros (2003:8), os APLs são:

caracterizados pela proximidade geográfica, especialização setorial, predominância de pequenas e médias empresas (PMEs), cooperação interfirmas, competição interfirmas determinada pela inovação, troca de informações baseada na confiança socialmente construída, organizações de apoio ativas na oferta de serviços e parceria estreita com o setor público local. Seu dinamismo inovativo decorre do fato de ser um tipo de arranjo institucional específico e localizado, capaz de estabelecer o aprendizado coletivo interativo, que, por sua vez, é alimentado e induzido no tempo pelo próprio processo de competição entre as firmas do distrito.

Segundo Schmitz (1992) aglomerar-se facilita ganho na eficiência e na flexibilidade que são raramente atingidas por empresas pequenas dispersas. A proximidade geográfica é origem comum dos APLs, que tendem a estimular o estabelecimento de laços sociais entre os agentes (Britto e Albuquerque, 2001). Esse processo tem como característica marcante a ampliação da base de decisões autônomas por parte dos atores locais, colocando em suas mãos o destino da economia local ou regional (Amaral Filho, 2001).

Podemos encontrar na literatura diversas formas de classificação de APLs. Mytelka e Farinelli (2000) classificam os APLs em informais, organizados e inovativos. De acordo com o quadro 1, os arranjos informais caracterizam-se por uma maioria de pequenas e médias empresas, com alto grau de competição, baixo nível de exportação e de lançamento de produtos e mão de obra pouco qualificada. Esse tipo de arranjo não possui um ator que exerça a liderança e o nível de tecnologia é rudimentar. A capacidade inovativa, a confiança e a cooperação entre os atores não são significativas. 
Nos arranjos organizados, a mão de obra é mais qualificada e as capacidades gerenciais e tecnológicas são mais desenvolvidas. As PMEs envolvidas demonstram características de cooperação que promove maior capacidade tecnológica. Entretanto, ainda existe grande dificuldade de desenvolvimento de atividades inovadoras. Em arranjos inovativos existe uma estrutura difundida de elos e ligações, e cooperação entre os atores. A mão de obra é capacitada e é formada por empresas que possuem elevada capacidade inovativa. Esse arranjo é típico dos países centrais; os outros dois são característicos dos países periféricos.

Quadro 1

Tipologias de APLs e sua performance

\begin{tabular}{|llll|}
\hline Caracterização & APL informal & APL organizado & APL inovativo \\
\hline Existência de liderança & Baixa & Baixa e média & Alta \\
Tamanho das firmas & Micro e pequenas & MPME & MPME e grandes \\
Capacidade inovativa & Pequena & Alguma & Contínua \\
Confiança interna & Pequena & Alta & Alta \\
Nível de tecnologia & Pequeno & Médio & Médio \\
Linkages & Algum & Algum & Difundido \\
Cooperação & Pequena & Alguma e alta & Alta \\
Competição & Alta & Alta & Média e alta \\
Novos produtos & Poucos; nenhum & Alguns & Continuamente \\
Exportação & Pouca; nenhuma & Média e alta & Alta \\
\hline
\end{tabular}

Fonte: Mytelka e Farinelli (2000:12).

Através das tipologias busca-se compreender a dinâmica de transformação dos APLs em sistemas produtivos e inovativos locais. No entanto, apesar das duas abordagens valorizarem a concentração geográfica, o conhecimento local e a capacidade inovativa não procuram diagnosticar o que no ambiente local provocou o surgimento dos APLs, nem o que o sustente sob outro ponto de vista que não o econômico. 
Santos (2007) aponta os fatores que podem ser destacados como imprescindíveis, embora ainda não suficientes, para o desenvolvimento dos APLs, conforme segue:

1. sedes administrativas das empresas estarem no APL;

2. parte significativa das decisões de financiamento a investimento estarem no APL (com capital próprio ou de terceiros). Não pertencer a sistemas industriais periféricos;

3. propriedade de marcas e tecnologia de produtos serem, principalmente, de empresas cuja sede está no APL;

4. desenvolvimento de produtos no APL, desenvolvimento de máquinas e insumos especializados a ser realizado no APL;

5. cooperação institucionalizada oferecendo serviços fundamentais;

6. sensibilidade de entidades governamentais às necessidades do APL e estreita cooperação entre essas entidades e o representante das empresas;

7. cooperação institucionalizada oferecendo serviços fundamentais;

8. planejamento estratégico permanente e participativo no APL;

9. acesso à mão de obra especializada com capacitação para atividades criativas ou estratégicas do setor;

10. elevado grau de confiança mútua preexistente no local.

Os fatores supra, vistos em conjunto, apresentam importância fundamental para o desenvolvimento e crescimento dos APLs e, principalmente, para a transformação dos que se encontram em seus estágios iniciais (informais), em APLs organizados e inovativos.

\section{Políticas públicas para o desenvolvimento dos APLs}

O tema APL destacou-se como opção metodológica, ganhando prioridade para a política do governo federal, a partir de sua inclusão na política industrial, tecnológica e de comércio exterior (Pitce) e da publicação da Portaria Interministerial no 200, de 2 de agosto de 2004, criando o grupo de trabalho permanente (GTP) para APLs, integrado pelo Ministério do Desenvolvimento, Indústria e Comércio Exterior (MDIC), o Ministério de Planejamento, Orçamento e Gestão (MPOG), o Ministério de Ciência e Tecnologia (MCT), o Ministério da Integração Nacional (MI) e mais 23 instituições, governamentais e não governamentais, de vários focos e matizes. 
O GTP elaborou um termo de referência (TR) para a política de apoio ao desenvolvimento de APLs, incluindo variáveis determinando a existência de um arranjo, as regras de atuação e a macroestratégia integrada. Pelo TR, um APL deve ter a seguinte caracterização: possuir um número significativo de empreendimentos e indivíduos no território; atuar em torno de uma mesma atividade produtiva predominante em que compartilhem formas percebidas de cooperação e algum mecanismo de governança, podendo incluir pequenas, médias e grandes empresas (MDIC, 2005).

A articulação das PMEs com o poder político local pode ser avaliada por diversos ângulos. As ações praticadas pelo poder local nos anos 1990 praticamente se resumiam à concessão de terrenos e de isenção de tributos estaduais e municipais - ICMS, IPTU e ISS - como forma de atrair negócios, o que redundava em críticas, por acarretar concorrência desleal aos APLs já existentes. Aos poucos, porém, prefeituras e agências de desenvolvimento de âmbito local têm aumentado a ênfase no apoio ao APL, sobretudo mediante desenvolvimento de infraestrutura e logística e com a criação de incubadoras, em conjunto com outros atores, além de parques industriais. Esse movimento reflete a maior articulação das PMEs em torno de associações empresariais locais, as quais passam a reivindicar ações do Estado (Ipea, 2005).

Os arranjos produtivos de PMEs no país mostram marcantes diferenças em termos de origem, setores de atividade, amadurecimento, formas de articulação e hierarquia entre as empresas e número e tipos de empresas, como exposto no quadro 1 . Há enorme diferença na complexidade, na intensidade e no dinamismo nas relações de cooperação existentes entre as empresas nos arranjos produtivos. Verifica-se o maior número de aglomerações no Brasil nos setores de atividade tradicionais (indústria tradicional, agropecuária e turismo), que, em geral, são as mais antigas e de maior dimensão econômica (Crocco et al., 2003).

As pesquisas sobre aglomerados produtivos têm gerado duas principais conclusões às políticas públicas:

- aglomerados locais bem-sucedidos não podem ser criados do nada; é preciso haver uma massa crítica de empreendimentos e capacitações (não importando quão rudimentares) que as ações de promoção possam mobilizar;

v o apoio dos governos aos aglomerados locais funciona melhor quando a política industrial é descentralizada e construída em torno de parcerias público-privadas (Schmitz, 2005:338).

Há, basicamente, dois mecanismos de elaboração de políticas locais para APLs. O primeiro mecanismo é denominado "de cima", por referir-se a uma fase 
constitucional, em que são estabelecidos os princípios gerais de aceitação dos caminhos de convergência entre os atores e também o tipo de processo decisório a ser adotado para as escolhas coletivas. O segundo mecanismo é denominado "de baixo", pois requer capacidade dos atores para promoverem ações que possibilitem a efetiva entrada e participação de todos (Casarotto, 2001). As políticas públicas para desenvolvimento dos APLs devem ter como principal objeto os ganhos de eficiências coletivas, por meio da viabilização de redes de cooperação entre as PMEs e os demais atores locais (Amato Neto, 2008).

Surge, portanto, um novo cenário das políticas governamentais, em que o desafio consiste em incorporar os atores locais na concepção e sustentação do processo de desenvolvimento, assim como:

articular os sujeitos locais - empreendedores públicos e privados, produtores de bens, serviços e cultura - para que, fortalecidos em sua autonomia, possam produzir um projeto estratégico de desenvolvimento regional e de inserção cooperativa e interdependente.

(Genro, 2007:5).

Destacar o desempenho dos atores locais, sobretudo dos empresários e sociedade civil, não significa negligenciar o fortalecimento das funções reguladoras e de coordenação do governo estadual, nem deixar de lado o valor do governo federal, no tocante à transferência de recursos aos estados e comunidades locais. É necessário, portanto, constituir sistemas de cooperação e apoio mútuo entre esferas governamentais, protegendo a integração nacional e incitando parcerias estratégicas, no espírito de uma federação cooperativa (Costa e Cunha, 2002). Houve, então, a necessidade de articulação das PMEs com instituições estatais e paraestatais.

A articulação das PMEs com instituições de apoio de caráter estatal e paraestatal, tais como Sebrae, Serviço Nacional da Indústria (Senai), Institutos de Pesquisas Tecnológicas (IPTs), Empresa Brasileira de Pesquisa Agropecuária (Embrapa) e CTA é relevante e permite às empresas aglomeradas dispor de infraestruturas de: i) apoio à melhoria de qualidade (entidades de normatização, laboratórios de testes e controle de qualidade e centros de pesquisa); ii) capacitação de recursos humanos (treinamento e especialização profissional); e iii) disseminação de técnicas de gestão e de tecnologias (cursos e palestras direcionados ao desenvolvimento de capital intelectual, acesso a informações técnicas, produtivas e de mercado).

(Naretto, Botelho e Mendonça, 2004:73) 
As universidades e os centros de tecnologia têm desempenhado importante papel nas suas tarefas de ensino, formação e qualificação de pessoal e apoio ao acesso a serviços especializados. Contudo, ainda são raras, frágeis e informais as relações de cooperação para desenvolvimento conjunto de tecnologias de produtos e processos.

Mesmo em suas formas mais incompletas, os APLs geram impactos significativos sobre o desempenho das firmas, notadamente pequenas e médias, com reflexos na geração de empregos. Aglomerações territoriais de PMEs podem encorajar as dinâmicas de cooperação, aprendizagem e compartilhamento de informações entre as unidades produtivas, tornando-as mais eficientes e competitivas (Amorim, 1998).

Importante salientar, entretanto, que a gestão estratégica dos custos é um dos principais desafios, de ordem gerencial e financeira, que diariamente desafiam os gestores de PMEs, devido à importância dessa ferramenta de controle, gestão e informação, para fornecer subsídios para o processo decisório. Assim, se essa gestão não for eficiente, as decisões fatalmente afetarão os produtos e os custos de produção (Olave e Amato Neto, 2005).

Portanto, os APLs têm se tornado uma importante forma de promover o desenvolvimento econômico. Daí a relevância de "se desenvolver metodologias que ajudem os gestores de políticas de desenvolvimento a identificarem o surgimento desses arranjos" (Crocco et al., 2003:9).

Há duas linhas de abordagem de políticas implementadas em APLs. A primeira delas orienta-se para o apoio às diferentes formas de cooperação entre as PMEs, e entre elas e as instituições locais. Entre os principais estímulos dessa política destaca-se o fortalecimento de uma governança local e a democratização das externalidades, de forma a garantir a todos semelhantes condições de acesso às vantagens de proximidade. Na segunda linha, o Estado atua através de ações complementares, voltadas para a atração de investimentos, como a implementação de políticas fiscais e a melhoria de infraestrutura (Castilhos apud Fauré e Hasendeclever, 2007).

$\mathrm{O}$ verdadeiro critério de eficiência de qualquer política implementada em APLs é que essas ações devem gerar melhorias significativas na capacidade produtiva da comunidade local (Humbert, 2005). Para as políticas públicas em APLs, a conclusão que emerge é que as respostas estratégicas às pressões competitivas não podem depender exclusivamente de ações privadas, mas requerem iniciativas das agências públicas como elemento catalisador ou mediador (Schmitz, 2005). 


\section{Metodologia da pesquisa}

Esta pesquisa foi realizada segundo abordagem qualitativa para coleta e análise dos dados e se valeu da estratégia de estudo de caso. Segundo Triviños (1992), a pesquisa qualitativa permite analisar os aspectos implícitos ao desenvolvimento das práticas organizacionais e a abordagem descritiva é praticada quando o que se pretende buscar é o conhecimento de determinadas informações, e por ser um método capaz de descrever com exatidão os fatos e fenômenos de determinada realidade.

O estudo de caso é indicado para estudos em que se trabalha com um caso específico que se considera típico ou ideal para explicar certa situação, pois permite tratar um problema com maior profundidade e possibilita maior integração de dados. "Como esforço de pesquisa, o estudo de caso contribui, de forma inigualável, para a compreensão que temos dos fenômenos individuais, organizacionais, sociais e políticos (...) [e] permite uma investigação para se preservar as características holísticas e significativas dos eventos da vida real" (Yin, 2001:21).

$\mathrm{O}$ desenvolvimento da pesquisa se deu em dois momentos principais. $\mathrm{O}$ primeiro constou do levantamento bibliográfico dos pressupostos teóricos necessários ao estudo. $\mathrm{O}$ segundo consistiu na entrada em campo, feita a partir de três fontes distintas de evidências na coleta de dados: entrevista, análise documental e observação direta não participante. Especificamente com relação às entrevistas, foram concebidos dois roteiros: um, para entrevista com os responsáveis pelos projetos de desenvolvimento do APL e outro, para o público-alvo dos projetos (criadores de ovinos e caprinos). Para construção desses dois instrumentos recorreu-se, em especial, ao levantamento de políticas públicas de desenvolvimento e fortalecimento do APL de ovinocaprinocultura, além do referencial teórico construído para este estudo.

A pesquisa de campo foi conduzida em abril de 2008 e as 13 entrevistas realizadas foram dispostas da seguinte forma: dois representantes do Sebrae Quixadá, três representantes da Prefeitura Municipal de Quixadá, um representante da Acocece (Associação de Criadores de Ovinos e Caprinos do Estado do Ceará), um representante da ACCALQ (Associação dos Criadores de Cabra Leiteira de Quixadá), além de seis produtores.

\section{Contexto da pesquisa: o ambiente institucional Quixadá}

O município de Quixadá está situado no sertão central do Ceará, distante $174 \mathrm{~km}$ de Fortaleza. O acesso se faz pelas rodovias CE-060 e CE-452. De 
acordo com a última divisão territorial, verificada em 1995, o município compreende 13 distritos: Califórnia, Cipó dos Anjos, Custódio, Daniel de Queiroz, Dom Maurício, Juá, Juatama, Riacho Verde, Sede, São Bernardo, São João dos Queiroz, Tapuiará e Várzea da Onça. Quixadá ocupa uma área de $2.059 \mathrm{~km}^{2}$, com uma população estimada em 69.654 habitantes e densidade populacional de $33,8 \mathrm{hab} . / \mathrm{km}^{2}$ (IBGE, 2000).

Quixadá é um dos centros comerciais mais expressivos do Ceará, para onde afluem as comunidades das cidades vizinhas. A maior fonte de empregabilidade é a administração pública, com mais de 2 mil funcionários. As principais atividades econômicas estão relacionadas à prestação de serviços e ao comércio. Em seguida vem a avicultura e a ovinocaprinocultura.

A ovinocaprinocultura em Quixadá está associada à presença de atores expressivos na região, como, por exemplo, a Associação de Criadores de Caprinos e Ovinos do Estado do Ceará (Acocece), composta pelos médios e grandes produtores, um frigorífico com tecnologia para beneficiar a carne dos ovinos e caprinos e ainda aspectos climáticos da região. Como em todo o Nordeste, chove pouco em Quixadá, cujas médias pluviométricas variam entre $500 \mathrm{~mm}$ e $700 \mathrm{~mm}$ ao ano. O período seco ocorre no segundo semestre, quando as médias térmicas máximas situam-se entre $32^{\circ} \mathrm{C}$ e $36^{\circ} \mathrm{C}$. Assim, plantas e animais adaptam-se com estratégias especiais para sobreviver com o mínimo de água.

A ovinocaprinocultura na região estabeleceu uma quebra de paradigmas, pois a atividade mais comum era a bovinocultura. Para a criação de boi fazia-se necessária uma maior extensão de terra com pasto e o gasto com a manutenção do rebanho também era maior, tornando-se inviável para o pequeno produtor. Por outro lado, a ovinocaprinocultura se adaptou perfeitamente à região, por se tratar de um rebanho que não necessita tanto de água, sendo de fácil alimentação, já que o clima da região é semiárido, com poucas chuvas, incluindo um grande período de estiagem.

Na seção seguinte ficarão explícitas algumas ações que ajudaram no desenvolvimento da ovinocaprinocultura em Quixadá.

\section{Análise dos resultados}

De acordo com o referencial teórico estudado sobre desenvolvimento local e aglomerações de empresas, percebe-se, com esta pesquisa, que o desenvolvimento da região está ligado ao desenvolvimento do APL de ovinocaprinocultura, pois tem havido um despertar e uma mobilização do poder público para 
a emergência das potencialidades locais. Atrelado a esse processo é evidente a busca da melhoria da condição financeira da comunidade, por meio da capacitação e de diversas formas de incentivos ministrados, conforme se constata ao longo desta seção.

O APL de ovinocaprinocultura em Quixadá tem sido considerado importante para o crescimento da competitividade e a melhoria das condições de vida das pessoas que habitam a região, o que só vem a corroborar o que Piore e Sabel (1984), Becattini (apud Pyke, Becattini e Sengenberger, 1990) e Storper (1997) afirmam sobre as regiões em que estão presentes esses tipos de aglomeração.

Em relação ao tipo de aglomeração (Mytelka e Farinelli, 2000), podese dizer que o APL estudado apresenta características de um APL organizado, devido ao tamanho das firmas, capacidade inovativa e a criação de novos produtos, porquanto ali são ainda encontrados traços de um APL informal, como, por exemplo, baixa liderança, pequena cooperação e nenhuma exportação.

Por meio da pesquisa de campo foi possível perceber algumas ações e políticas desenvolvidas no APL de ovinocaprinocultura. As ações identificadas, por intermédio das entrevistas, permitiram a formulação de categorias de análises, descritas no quadro 2.

Quadro 2

Categorias de ações e políticas públicas implementadas no APL de Quixadá

\begin{tabular}{|c|c|}
\hline Categorias & Descrição sumária das ações e políticas \\
\hline $\begin{array}{l}\text { Aumento de } \\
\text { produtividade }\end{array}$ & $\begin{array}{l}\text { V Auxílio na diminuição da mortalidade e técnicas de plantio para } \\
\text { alimentação. }\end{array}$ \\
\hline \multirow[t]{2}{*}{ Capacitação } & $\begin{array}{l}\text { V Capacitação de } 80 \text { produtores com técnicas para a ovinocaprinocultura, } \\
\text { pelo projeto Aprisco (Sebrae), incluindo manejo do rebanho. }\end{array}$ \\
\hline & $\begin{array}{l}\text { V Assistência a } 1.500 \text { produtores, através do Programa de Melhoramento } \\
\text { Genético da Ovinocaprinocultura, da prefeitura. }\end{array}$ \\
\hline Inovação na gestão & $\boldsymbol{\nabla}$ Produzir precocemente. \\
\hline \multirow[t]{3}{*}{ Inovação tecnológica } & V Vacinação e vermifugação do rebanho. \\
\hline & V Instalação de fábrica de laticínio de leite de cabra. \\
\hline & $\boldsymbol{\nabla}$ Desenvolvimento de novos produtos. \\
\hline \multirow[t]{2}{*}{ Linhas de crédito } & $\mathbf{v}$ Financiadores do projeto Aprisco (Sebrae, Embrapa, Senar, Faec). \\
\hline & $\begin{array}{l}\text { V Programa de Melhoramento Genético da Ovinocaprinocultura } \\
\text { (financiado pela Fundação Banco do Brasil). }\end{array}$ \\
\hline Qualidade do rebanho & $\boldsymbol{\nabla}$ Investimento em genética. \\
\hline & V Uso de inseticida orgânico nos alimentos do rebanho. \\
\hline
\end{tabular}

Fonte: Dados da pesquisa. 
Nesses termos, optou-se pela análise dos resultados a partir das categorias identificadas. Nas próximas subseções detalhar-se-á cada categoria apresentada sucintamente no quadro 2 , buscando-se corroborar o resultado da pesquisa com o referencial teórico adotado. Adicionalmente, uma última seção, denominada comentários adicionais, relata os entraves e limitações para o desenvolvimento do APL.

\section{Aumento de produtividade}

O quadro da ovinocaprinocultura em Quixadá anterior ao desenvolvimento do APL apresentava uma baixa produtividade em rebanhos devido a condições inadequadas de alimentação e manejo, e aos ineficientes controles sanitários e processos de reprodução, tornando-se obstáculos à expansão da atividade. Dessa forma, foram implementadas algumas ações para o aumento da produtividade do plantel, conforme descrição dos entrevistados:

No primeiro momento do projeto, tentamos trabalhar a redução da mortalidade do rebanho e foi um dos maiores resultados alcançados dentro do programa, isso graças a algumas técnicas de manejo do rebanho.

(Entrevistado 1)

Percebe-se que devido às ações do projeto Aprisco, do Sebrae/Quixadá, foi alcançado um fortalecimento desse APL, pois as técnicas de manejo ensinadas aos produtores os preveniram de doenças fáceis de serem evitadas e que antes eram causas de morte do rebanho. Com relação às técnicas de plantio para alimentação é ilustrativa a fala de um produtor:

Aqui, nós temos que ter um animal que tenha suporte; foi preciso a técnica para nos aconselhar tanto no sistema do manuseio, como assepsia dos borregos, (...) como poderia sustentar esses animais no verão. Então, a prefeitura entrou com o secretário de agricultura e disse: nós vamos educar o homem do campo a fazer forragem, nos ensinou a plantar, passamos a plantar o sorgo, o milho, a caninha-da-índia e a fazer a silagem. Para começar, o prefeito achou muito bom e, com o secretário e seus técnicos, deu 100\% de tudo isso: o trator, as sementes (...) plantava as sementes, fazia o silo, pagava o silo e ainda amarrava a máquina por conta dele, afinal, nós podemos ver que em dois anos, ele já foi educando a gente e no terceiro ano, quarto ano em diante, disse: agora pronto, vocês vão ter a técnica e a lona! Muita gente dizia: "não, agora é que vai cair 
tudo. Pelo contrário, fez foi dobrar o valor em toneladas. Porque quem aprendeu a fazer o silo, hoje não sabe viver sem silo. Este ano, eu já plantei oitenta toneladas de milho e vinte de caninha-da-índia. A gente criava sem o silo, mas quando chegava o inverno as ovelhas todas "mujavam", chegava o verão elas não tinham o que comer, morria o borrego. Não tinha o que dar de comer, era prejuízo na certa.

(Entrevistado 5)

Também foi visto que a técnica de alimentação do rebanho, ensinada pelos técnicos da Secretaria de Agricultura de Quixadá, possibilitou a sustentabilidade do rebanho na época de estiagem. De acordo com os entrevistados, a prefeitura, em parceria com os pequenos agricultores, promoveu a silagem de 4.700 toneladas de grãos que serviram de forragem para a alimentação animal no período em que se esgotou a mata nativa. A administração pública pagou o aluguel da máquina ensiladeira, material de consumo, como cordas e lonas, e $40 \%$ da mão de obra. Esse projeto tem o objetivo de garantir uma renda mínima para o agricultor, mesmo no período da estiagem. Os participantes da silagem puderam manter sua pecuária, mesmo sem pasto natural, gerando produção. E quem não possuía criação pôde vender a forragem a um preço elevado pela demanda. Dessa forma, pode-se dizer que essa política atingiu o critério de eficiência, segundo Humbert (2005), de que qualquer política implementada em APLs deva gerar melhorias significativas na capacidade produtiva da comunidade local.

\section{Capacitação}

A capacitação é imprescindível para dar continuidade à atividade, já que o aumento da produtividade e, por conseguinte, do rebanho implicam maiores níveis de desempenho. O baixo desempenho pode onerar significativamente os custos, inviabilizando maiores escalas de produção, e pode ainda acarretar em outras desvantagens, principalmente as comerciais.

A carência técnica nas propriedades, antes do projeto, era muito grande no estado; praticamente $90 \%$ do que a gente tentou atender (...) nunca recebeu atendimento técnico, orientação técnica na ovinocaprinocultura. (...) Conseguimos implementar algumas técnicas em relação ao manejo do rebanho, cura e desinfecção do umbigo; em alguns raros casos, conseguimos a mineralização do rebanho.

(Entrevistado 1) 
Sem a secretaria de agricultura, sem a técnica, hoje nós fecharíamos a porta, é como um hospital sem médico (...) pode ter o remédio que tiver, se você não souber se medicar, como é que vai ser? Então essa é a minha opinião e o meu desenvolvimento, que vocês já viram como é, como pequeno que sou, mas que venho sempre dentro da técnica.

(Entrevistado 5)

$\mathrm{Na}$ visitação às fazendas dos produtores percebe-se que já existe uma boa estrutura para o rebanho, devido ao ensinamento ministrado, que ajudou a desenvolver uma conscientização sobre os cuidados com os animais. Além disso, evidencia-se, pelos depoimentos colhidos, a preocupação de praticar o que foi aprendido, considerado de suma importância, pois, antes de aplicar as novas técnicas, alguns fazendeiros haviam perdido todo o seu rebanho.

No tocante à capacitação, percebe-se que a política pública atingiu seu principal objetivo, com ganhos em eficiência coletiva (Amato Neto, 2008), por meio da melhoria de potencialidades através de ações entre os pequenos produtores, a prefeitura e o Sebrae, possibilitando ganhos significativos para os produtores.

\section{Inovação na gestão}

A forma com que os produtores tentam gerir sua produção muitas vezes está ultrapassada. São utilizados conhecimentos empíricos, que passam de pai para filho e não conseguem modificar a visão de mero produtor (criador) para empresário. É importante que os produtores modifiquem essa mentalidade, para que possam crescer e conseguir sustentabilidade da atividade.

Tentamos sensibilizar o produtor a produzir um animal comercialmente viável, o produtor era acostumado a produzir um animal de 18 meses ou mais para que ele conseguisse ter uma estrutura corpórea. Mostramos que isso era comercialmente inviável, pelo tempo e a demora, o retorno sobre esses investimentos era muito baixo. O animal comercialmente viável começa de três a oito meses, o animal tem que ter em torno de 30 quilos, ninguém quer comer um animal que ficou 18 meses andando para a musculatura ficar rígida; o consumidor quer um animal tenro, que é o que a gente chama de cordeiro precoce; eu não consigo melhorar seu preço de mercado, o que eu consigo é melhorar o seu custo de produção. A gente tem alguns resultados desse nível de entendimento.

(Entrevistado 1) 
A gestão dos custos é um problema que preocupa os técnicos do Sebrae, pois os produtores não conseguem trabalhar com a escrituração, ou seja, o controle de quanto aquele animal vai custar ao produtor pelo tempo em que ele está na sua fazenda. É algo cultural. De acordo com Olave e Amato Neto (2005), essa gestão é essencial para auxiliar na tomada de decisão. Apesar de já se ter uma consciência de se produzir precocemente, é de grande necessidade mudar a cultura dos produtores, para que eles controlem os gastos com seu rebanho, para que eles tenham uma ideia palpável de seu custo de produção e não fiquem se baseando em meras suposições que não irão ajudá-los a crescer.

\section{Inovação tecnológica}

Santos (2007) descreve a tecnologia e o desenvolvimento em novos produtos, como um dos fatores indispensáveis ao desenvolvimento do APL, ou seja, quanto maior o nível de inovação tecnológica no APL, mais ele estará fortalecido e preparado para conquistar novos mercados. De acordo com as falas de alguns entrevistados é possível identificar o nível de inovação tecnológica apresentado pelo APL, conforme segue:

Não tinha nenhum tipo de vermifugação e vacinação, coisa que foi adotada na região; o rebanho é $100 \%$ vacinado e vermifugado, graças às ações do projeto Aprisco, juntamente com os parceiros.

(Entrevistado 1)

Na visitação às propriedades pôde-se observar que há o chamado "corredor de pega", para a vacinação e vermifugação de animais, o que anteriormente não existia. Para vacinar o rebanho, o técnico despendia muito tempo e esforço na tentativa de levar cada animal para o local da aplicação, o que, algumas vezes, não conseguia devido à falta de infraestrutura adequada, além de também estressar o rebanho. A nova estrutura foi montada graças às recomendações dadas pelos técnicos do Sebrae e da Secretaria de Agricultura.

A prefeitura está construindo uma fábrica de laticínio de leite de cabra. Porque temos uma grande produção de leite, mas os produtores não têm como beneficiar esse leite de cabra.

(Entrevistado 2)

Graças à tecnologia, hoje nós temos o queijo de cabra, o iogurte de cabra e algum artesanato ligado ao couro do carneiro e do bode.

(Entrevistado 4) 
Contudo, apesar do número relativamente grande de inovações em termos de produtos e processos, para um setor de atividades primárias (Santos, 2007) é patente o nível artesanal em que se dá à produção desses novos produtos. O indicativo, nesse caso, é que com o aumento da demanda, em função da aceitabilidade dos novos produtos, um nível maior de tecnologia deva ser utilizado, implicando em maiores investimentos e capacitações, algo que poderá tornar o empreendimento inviável para o pequeno produtor e para o médio produtor.

A melhoria dos processos e dos produtos é um dos fatores responsáveis pela promoção e pelo aprimoramento produtivo de um aglomerado de empresas (Schmitz, 2005), e no caso específico de Quixadá, é possível afirmar que o desenvolvimento ocorrido é seguramente suportado pelo incremento tecnológico descrito.

\section{Linhas de crédito}

Para que os pequenos e médios produtores consigam dar início ou continuidade a sua produção, torna-se necessário o apoio financeiro. É fundamental a busca dos órgãos apoiadores da atividade na região por financiamentos para os projetos envolvidos.

Em 2005, o Sebrae desenvolveu o Projeto Aprisco, que contou com a parceria da Embrapa, do Senar e da Faec.

(Entrevistado 1)

Em 2005 foi aprovado um projeto em parceria com a Fundação Banco do Brasil e está sendo feita a compra de 95 reprodutores puros de origem e 35 matrizes entre cinco raças de ovinos e caprinos para corte e para leite.

(Entrevistado 2)

A ovinocaprinocultura em Quixadá tem merecido um olhar especial do gestor do município e do Sebrae, sendo considerada uma das atividades mais vantajosas para a região, o que vem chamando a atenção de alguns órgãos que têm se colocado à disposição para apoiar os projetos financeiramente. Esses apoios vêm estimulando o fortalecimento do APL de ovinocaprinocultura em Quixadá, o que garante certo contentamento aos produtores.

Foi detectada a capacidade do poder público para atrair novos investimentos externos, que é um dos fatores que reforçam a potencialidade da 
comunidade, bem como se coaduna com a percepção de Schmitz (2005), de que o poder público tem de intervir para o desenvolvimento do APL. Por meio do projeto aprovado pela Fundação Banco do Brasil, o APL de ovinocaprinocultura será fortalecido ainda mais.

\section{Melhoria da qualidade do rebanho}

A ovinocaprinocultura em Quixadá ganhou uma grande repercussão, graças à qualidade do rebanho encontrado no local. O investimento nessa melhoria é necessário para a realização e participação em feiras e exposições que acontecem na região, nas quais comparecem produtores de todos os estados do país.

Em 2004, a prefeitura começou a trabalhar com a ovinocaprinocultura e começou a comprar alguns reprodutores puros de origem para melhorar o rebanho. Em 2005, projeto em parceria com a Fundação Banco do Brasil fez a compra de 95 reprodutores puros de origem e 35 matrizes entre cinco raças de ovinos e caprinos para corte e para leite. As matrizes ficam em uma estrutura feita para elas, para a renovação do plantel. Esse programa chama-se Programa de Melhoramento Genético na Ovinocaprinocultura.

(Entrevistado 2)

Nós começamos a trabalhar por conta própria; cheguei a comprar 100 ovelhas Santa Inês e chegamos a produzir 80 borregos, mas não consegui salvar nem $20 \%$, porque não havia técnica. A gente começou com as nossas próprias forças, mas aí a Secretaria de Agricultura Familiar entrou com os técnicos, dando-nos apoio, e começou a nos ensinar, tanto o manuseio, como o tipo de ovelha que deveríamos comprar.

(Entrevistado 5)

Em se tratando de melhoria genética, o reprodutor puro de origem está sendo bastante útil para os produtores, que ficam com o animal em seu poder durante dois meses, para cruzar com as fêmeas de raças inferiores, com ganho de qualidade para o borrego. Foram vistas nas propriedades várias linhagens dessa mistura de raças, que, além de dar mais beleza, valoriza o rebanho. Os produtores mostram as misturas de raças com satisfação, pois, sem esse empréstimo seria impossível o melhoramento genético, geralmente bastante oneroso.

Ainda com relação à qualidade do rebanho, o entrevistado 5 descreve uma receita de orgânica para controle de pragas, composta por uma mistura 
de cal comum e enxofre, que é cozida e depois reservada, e então colocada em uma bomba para pulverizar a plantação. Essa receita é ensinada pelos técnicos da Secretaria da Agricultura para pulverizar a vegetação que vai alimentar os animais, sem qualquer risco de dano para o produtor e para o rebanho.

\section{Comentários adicionais}

A pesquisa revela um quadro de desenvolvimento da região em torno dessa atividade, mas que pode se fortalecer ainda mais, através da implementação de um conjunto de ações que venham a eliminar ou minimizar alguns entraves que têm impedido o crescimento da atividade na região.

De acordo com as entrevistas aplicadas foram detectados alguns gargalos que impedem que o APL de ovinocaprinocultura chegue ao final do ciclo de produção com sucesso e continuidade. Um desses gargalos é a comercialização da carne. Ainda existe certo preconceito no interior contra a carne "resfriada". Esse tipo de carne é visto como "carne de defunto". Carne fresca é aquela exposta, "pingando sangue". Faz-se necessária a utilização de alguma ação de informação, que venha a desmitificar esse bloqueio por parte dos consumidores, essa forma cultural de pensar.

Outra dificuldade enfrentada consiste na comercialização do leite de cabra. Os produtores produzem leite, mas não têm para quem vender. A proposta deles é fazer com que o governo do estado compre esse leite, para a merenda escolar, garantindo assim uma continuidade na produção e, ao mesmo tempo, deixando os produtores seguros para trabalhar com mais afinco na atividade.

O Programa de Melhoramento Genético da Ovinocaprinocultura, da Secretaria de Agricultura de Quixadá, procura difundir com o setor agropecuário, especialmente os produtores de caprinos e ovinos, a adoção de tecnologias e a organização da produção, que não podem ser vistas como atividades restritas "às porteiras da propriedade". Portanto, para que a ovinocaprinocultura possa se desenvolver e conquistar posição de destaque na economia da região, faz-se necessário que a tecnologia e a organização da produção sejam adotadas em todos os segmentos da produção, principalmente manejo alimentar, sanitário, reprodutivo, escrituração zootécnica e comercialização.

Apesar das dificuldades relatadas, a pesquisa de campo possibilitou constatar que as políticas públicas para o referido APL apresentam articulação com o poder local e os demais atores sociais envolvidos nas atividades produtivas, e que elas podem ter bons resultados. Contudo, ainda é incipiente a 
efetiva participação da comunidade no planejamento das atividades e ações do APL, condição necessária para o fortalecimento de sua autonomia, conforme ratifica Genro (2007).

\section{Considerações finais}

A pesquisa procurou, primordialmente, analisar o impacto das políticas públicas implementadas no arranjo produtivo local de ovinocaprinocultura em Quixadá-CE, salientando as ações de maior importância para o desenvolvimento e fortalecimento desse APL. De acordo com o objetivo definido, as diretrizes e práticas das políticas públicas ali implementadas estão voltadas para várias áreas dentro da ovinocaprinocultura, como, por exemplo, o melhoramento genético do rebanho, medidas sanitárias, manejo dos animais, produção de alimentos com a utilização de técnicas baratas e adaptáveis ao clima da região para o sustento do rebanho. Assim, é evidente o impacto das ações políticas para o fortalecimento e sustentabilidade à atividade em Quixadá.

Ainda em resposta ao problema de pesquisa, o estudo de campo possibilitou a verificação do desenvolvimento do APL, com melhoramento na estrutura para os animais (com a eliminação de doenças reincidentes que causavam morte), com a melhoria da qualidade do rebanho (por meio do cruzamento com raças puras), aumento do número de animais nas fazendas e a fabricação de novos produtos, como o iogurte de leite de cabra.

Pelos resultados destaca-se o desenvolvimento local na região, a partir da transformação consciente da realidade, interessada não apenas com a geração presente, mas também com as futuras. Tal desenvolvimento é evidenciado pela preocupação com os aspectos ambientais que a atividade enseja, como a técnica de vermifugação observada, que não é nociva ao ambiente e às pessoas, além de técnicas especiais de plantio para alimentação, garantindo assim o uso adequado da terra.

Com os projetos apoiadores da ovinocaprinocultura em Quixadá, tornou-se possível a sobrevivência do pequeno produtor e de sua família. Ele pode usar o seu rebanho como moeda de valor, comercializando-o informalmente nas feiras semanais que acontecem na cidade. Antes do trabalho realizado pelos projetos, esses animais não tinham boa cotação no mercado, o apoio técnico ministrado trouxe valorização dos ovinos e dos caprinos. É certo que tudo o que foi feito em torno da atividade gerou uma melhoria da qualidade de vida das pessoas da região. 
Esta pesquisa possibilitou constatar a adequação da ovinocaprinocultura em Quixadá, evidenciando que, com o apoio do poder público, a comunidade apresenta capacidade de melhor utilização das características naturais específicas da região a seu favor. Foi percebido que, por meio desse apoio técnico ministrado aos criadores, a comunidade tem elevado o nível educacional para lidar com a atividade e que o poder local tem decidido apoiar totalmente essa atividade.

Por fim, espera-se que esta pesquisa possa fazer desencadear uma discussão sobre as necessidades de políticas públicas capazes de dar sustentabilidade aos arranjos produtivos locais nos diversos setores, para que haja crescimento econômico e possíveis vantagens competitivas. E que tal debate possa aportar subsídios que contribuirão para desenvolver ações de políticas públicas voltadas para esses aglomerados.

\section{Referências}

AMARAL FILHO, Jair do. A endogeneização no desenvolvimento econômico regional e local. Ipea - Planejamento e políticas públicas, n. 23, jun. 2001. Disponível em: </www.ipea.gov.br/pub/ppp/ppp23/Parte1.pdf>. Acesso em: 12 set. 2007.

AMATO NETO, João. Redes de cooperação produtiva e clusters regionais: oportunidades para as pequenas e médias empresas. São Paulo: Fundação Vanzolini/Atlas, 2008.

AMORIM, Mônica Alves. Clusters como estratégia de desenvolvimento industrial no Ceará. Fortaleza: Banco do Nordeste, ETENE, 1998.

BANCO DO NORDESTE. Caderno de ovinocaprinocultura. Fortaleza: BNB, 1999.

BRITTO, Jorge; ALBUQUERQUE, Eduardo da Motta. Estrutura e dinamismo de clusters industriais na economia brasileira: uma análise a partir de dados da Rais. In: TIRONI, F. Industrialização descentralizada: sistemas industriais locais. Brasília: Ipea, 2001.

CÂMARA, Márcia Regina Gabardo da et al. Cadeia têxtil: discutindo a formação de um arranjo produtivo local na Região Metropolitana de Londrina-Paraná. In: ENCONTRO ANUAL DA ASSOCIAÇÃO NACIONAL DOS PROGRAMAS DE PÓSGRADUAÇÃO EM ADMINISTRAÇÃO - ENANPAD, 29. Anais... Rio de Janeiro: Anpad, 2005. 1 CD-ROM. 
CASAROTTO FILHO, Nélson; PIRES, Luís Henrique. Redes de pequenas e médias empresas e desenvolvimento local: estratégias para a conquista da competitividade global com base na experiência italiana. 2. ed. São Paulo: Atlas, 2001.

CASSIOLATO, J.; LASTRES, H. M. M. Políticas para promoção de arranjos produtivos e inovativos locais de micro e pequenas empresas: conceito, vantagens e restrições de equívocos usuais. Rio de Janeiro: RedeSist, 2003.

COSTA, Frederico Lustosa da; CUNHA, Augusto Paulo Guimarães. Pensar o desenvolvimento a partir do local: novo desafio para os gestores públicos. In: CONGRESO INTERNACIONAL DEL CLAD SOBRE LA REFORMA DEL ESTADO Y DE LA ADMINISTRACIÓN PÚBLICA, 7. Anales... Lisboa, Portugal, 8-11 Oct. 2002. Disponível em: <http://unpan1.un.org/intradoc/groups/public/documents/CLAD/clad0044418. pdf $>$. Acesso em: 25 out. 2007.

CROCCO, Marco Aurélio et al. Metodologia de identificação de arranjos produtivos locais potenciais. Cedeplar, jul. 2003. (Texto para Discussão, n. 212).

FAURÉ, Ives; HASENDECLEVER, Lia (Orgs.). Caleidoscópio do desenvolvimento local no Brasil. E-papers, 2007.

GENRO, Tarso. Entrevista concedida à Revista Eletrônica de Administração — Read, v. 6, n. 3, 15. ed., out. 2000. Disponível em: <http://read.adm.ufrgs.br/edicoes/ busca.php>. Acesso em: 17 set. 2007.

HUMBERT, Marc. Globalização e glocalização: problemas para países em desenvolvimento e implicações para políticas supranacionais, nacionais e subnacionais. In: SEMINÁRIO INTERNACIONAL CONHECIMENTO, SISTEMAS DE INOVAÇÃO E DESENVOLVIMENTO. Anais... Instituto de Economia da Universidade Federal do Rio de Janeiro, 18 a 19 de agosto de 2005.

IBGE. Instituto Brasileiro de Geografia e Estatística. Censo da população por municípios Ceará. 2000. Disponível em: <www.ibge.gov.br/home/ presidencia/ noticias/20122002censo.shtm>. Acesso em: 13 abr. 2008.

IPEA. Instituto de Pesquisa Econômica e Aplicada. Planejamento e políticas públicas, n. 27. jun./dez. 2004/2005.

MINISTÉRIO DO DESENVOLVIMENTO INDUSTRIAL E DE COMÉRCIO EXTERIOR (MDIC). Grupo de trabalho permanente. Brasília, 2005.

MYTELKA, L. K.; FARINELLI, F. Local clusters, innovation systems and sustained competitiveness. In: SEMINÁRIO ARRANJOS E SISTEMAS PRODUTIVOS LOCAIS E AS NOVAS POLÍTICAS DE DESENVOLVIMENTO INDUSTRIAL E TECNOLÓGICO. Anais... Rio de Janeiro: Instituto de Economia/UFRJ, 2000. 
NARETTO, Nílton; BOTELHO, Marisa dos Reis; MENDONÇA, Maurício. A trajetória das políticas públicas para pequenas e médias empresas no Brasil: do apoio individual ao apoio a empresas articuladas em arranjos produtivos locais. Ipea - Planejamento e Políticas Públicas, n. 27, jun./dez. 2004.

OLAVE, Maria Elena Leon; AMATO NETO, João. A formação de redes de cooperação e clusters em países emergentes: uma alternativa para as PMEs no Brasil. In: AMATO NETO, João. (Org.). Redes entre organizações. São Paulo: Atlas, 2005.

PIORE, M.; SABEL, C. The second industrial divide: possibilities for prosperity. New York: Basic Books, 1984.

PYKE, F.; BECATTINI, G.; SENGENBERGER, W. Industrial districts and inter-firm cooperation in Italy. Geneva: International Institute for Labour Studies (ILO), 1990.

SANTOS, Juleísa Albuquerque dos. Caracterização do perfil empreendedor como facilitador das iniciativas de desenvolvimento local. Dissertação (Mestrado em Desenvolvimento Local) - Universidade Católica Dom Bosco (UCDB), Campo Grande, MS, 2007.

SCHMITZ, H. On the clustering of small firms. Institute of Development Studies (IDS Bulletin), Brigton, v. 23, n. 3, 1992.

. Aglomerações produtivas locais e cadeias de valor: como a organização

das relações entre empresas influencia o aprimoramento produtivo. In: LASTRES, H.; CASSIOLATO, J. E.; ARROIO, A. Conhecimento, sistemas de inovação e desenvolvimento. Rio de Janeiro: UFRJ/Contraponto, 2005.

STORPER, M. The regional world: territorial development in a global economy. London/New York: The Guilford Press, 1997.

TRIVIÑOS, Augusto Nibaldo Silva. Introdução à pesquisa em ciências sociais: a pesquisa qualitativa em educação. 3. ed. São Paulo: Atlas, 1992.

YIN, Robert K. Estudo de caso: planejamento e métodos. Porto Alegre, Bookman, 2001. 